\title{
Predicting Covid-19 Preventive Healthy Behaviors Based on Dysfunctional Attitudes in Five Countries
}

\author{
Sima Eivazi (iD ${ }^{1}$, Jahangir Karami (iD ${ }^{2,}{ }^{,}$, Peter John Varey ${ }^{3}$ and Sara Eivazi ${ }^{4}$ \\ ${ }^{1}$ Psychology Department, Razi University, Kermanshah, Iran \\ ${ }^{2}$ Department of Family Studies, Razi University, Kermanshah, Iran \\ ${ }^{3}$ Public Health Specialist, Manchester, UK \\ ${ }^{4}$ Siavash Consulting Limited, Manchester, UK \\ "Corresponding author: Department of Family Studies, Razi University, Kermanshah, Iran. Email: j.karami@razi.ac.ir
}

Received 2020 July 14; Revised 2020 October 05; Accepted 2020 October 06.

\begin{abstract}
Background: Dysfunctional attitudes are biased assumptions and beliefs that the subject has toward himself, his surroundings, and the future world.

Objectives: The present study aimed to predict COVID-19 preventive healthy behaviors based on dysfunctional attitudes in five countries.

Methods: This was a descriptive, correlational study, and the statistical population of the study included all individuals over the age of 18 years residing in Iran, Australia, England, Sweden, and Canada. Subjects were selected by the voluntary sampling method in the Spring of 2020. In total, 498 electronic questionnaires encompassing three sections of demographic characteristics, dysfunctional attitude scale (1987), and COVID-19 preventive health behaviors questionnaire (2020) were completed online. In addition, data analysis was performed in SPSS version 21 using Pearson's correlation coefficient and stepwise multiple regression.

Results: In this study, there was a significant negative relationship between dysfunctional attitudes and COVID-19 preventive healthy behaviors $(\mathrm{P}<0.001)$. In addition, perfectionism, gender, and age predicted healthy behaviors $(\mathrm{P}<0 / 001)$. The results of the comparison of Iran with other countries also demonstrated a significant reverse correlation between dysfunctional attitudes and healthy behaviors $(\mathrm{P}<0.001)$. Moreover, there was a significant association between marital status, age, level of education, gender $(\mathrm{P}<0.001)$, and economic status $(\mathrm{P}<0.05)$ with healthy behaviors in Iran while no significant relationship was observed in other countries studied in this regard.
\end{abstract}

Conclusions: It is suggested that workshops on changing dysfunctional attitudes and strengthening positive attitudes in community members be held in-person or via cyberspace before or during the occurrence of crises such as the COVID-19 outbreak.

Keywords: Healthy Behaviors, COVID-19, Dysfunctional Attitudes, Demographic Characteristics

\section{Background}

A new communicable disease called coronavirus disease or COVID-19 emerged in Wuhan, China in midSeptember, 2019, and rapidly spread throughout this country in a few days for various reasons (1) and then similar cases were reported in most of the other countries. On March 11th, 2020, the World Health Organization (WHO) announced the COVID-19 outbreak a pandemic (2). COVID19 is an acute severe respiratory disease that is closely related to SARS-CoV-2 (3). Early symptoms include fever, cough, respiratory problems, and severe cases experience pneumonia, acute respiratory syndrome, and eventually mortality (4). To date, no successful vaccine or antiviral drug has been clinically confirmed for the treatment of COVID-19, and the only way to prevent the disease and con- trol the infection is adherence to hygiene practices by the public (5). The COVID-19 disease is an important global crisis that has necessitated individuals, organizations, and countries to carry out necessary measures to deal with the phenomenon (6).

In general, health behaviors and habits of individuals affect the incidence and severity of diseases (7). The WHO (1998) defines self-care as the actions performed by an individual to maintain their psychological and physical health, meet their social and mental needs, prevent diseases and incidences, improve chronic illnesses and conditions and protect their health after an acute illness or hospital discharge (8). Core principles on self-care include participation and acceptance of responsibility by the individual so that disease complications could be controlled (9) or the 
emergence of a disease could be prevented by performing the related behaviors correctly. During a pandemic in society, such as COVID-19, self-care includes a series of health behaviors announced by the WHO that should be performed by all people. This is mainly due to the fact that the unhealthy behaviors of one person not only affect their own health but also have impacts on the health of other people in the community. Therefore, everyone is responsible for taking care of themselves and others. People may not perform healthy behaviors for various reasons; firstly, the person who should take care of himself has not accurately comprehended the problem. Secondly, he does not know the correct ways to deal with the problem, and thirdly, he may not that motivated to perform self-care behaviors (10).

Self-care is a function of factors such as knowledge, motivation, attitude, performance and skill, individual beliefs, and culture of society $(11,12)$. A reduction in social interactions always exposes community members to various stressors, which affects their functioning in society and satisfaction with life. These stressors can be a combination of internal stimuli, such as personality and beliefs, which lays the foundation for failure, and external factors, including environmental stressors (13). According to cognitive models, some of the factors affecting the emergence of depression and anxiety include cognitive distortions and dysfunctional attitudes. Dysfunctional attitudes are biased assumptions and beliefs that the subject has toward himself, his surroundings, and the future world (14). In addition, dysfunctional attitudes are considered as predisposing factors in the onset of depressive episodes directly or as a factor of individual vulnerability due to environmental stressors (15). These attitudes emerge immediately after the occurrence of unfortunate and negative life events and stimulate a negatively-biased pattern of information processing. In other words, they are determined by negative thinking patterns. These negative attitudes can be among the health dysfunctional factors (16). According to Beck, dysfunctional attitudes are inflexible and perfectionist standards used by the individual to judge themselves and others. These attitudes are considered dysfunctional due to being extreme, resilient, and inflexible (17). Negative beliefs and thoughts that people form put them under stress and decrease their quality of life in various ways (18). Moreover, dysfunctional attitudes negatively affect individual, social and occupational performance (19). Studies have reported a positive association between dysfunctional attitudes and depression (20).

Attitudes of people determine their behaviors (21). According to the theory of planned behavior, the intention to perform a self-care behavior is determined by three components: the attitude of the individual (an individual's as- sessment of the potential or expected outcome of performing a self-care behavior), subjective norms (the perceived social pressure to perform or not to perform the behavior), and perceived behavioral control (a person's understanding of the simplicity or difficulty of performing a selfcare behavior) (22). Studies show that attitude affects individuals' self-care against their disease (23-25). In addition, research has confirmed the relationship between attitude and behavioral intention and, ultimately, performing healthy behaviors $(26,27)$. A previous study was performed to evaluate the effect of self-care on dysfunctional attitudes, the results of which were indicative of a decrease in the mentioned attitudes after self-care training (19). These results demonstrated a correlation between dysfunctional attitudes and self-care. Various studies have shown a relationship between the demographic characteristics of individuals and healthy behaviors. In this regard, a significant association has been reported between self-care behaviors and variables of age, marital status, level of education, and economic status $(19,28,29)$.

Not only do diseases such as COVID-19 impose huge financial burdens on the health systems of all countries, but also, they are associated with undeniable human consequences and complications. Implementing preventive measures and increasing self-care skills is more effective than other measures in order to achieve favorable results (30). Given the negative role of dysfunctional attitudes in social and individual performance, it is crucial to conduct research on the relationship between these attitudes and healthy behaviors. While numerous studies have shown the association between attitude and healthy behaviors, no comprehensive research has been conducted on the relationship between demographic characteristics, dysfunctional attitudes, and performing healthy behaviors in such crises. With this background in mind, the present study aimed to evaluate the demographic characteristics and dysfunctional attitudes of individuals, which, according to the scientific background of the field, seem to be related to healthy behaviors that prevent COVID-19.

\section{Objectives}

The present study aimed to predict COVID-19 predictive healthy behaviors based on dysfunctional attitudes and selected demographic characteristics in five countries

\section{Methods}

This was a descriptive and correlational study, and the statistical population included all individuals aged above the age of 18 residing in Iran, Australia, England, Sweden, 
and Canada. Subjects were selected by the voluntary sampling method, for which electronic questionnaires were prepared by Porsall Website and a call was published for participation in the research through cyberspace. When 500 individuals announced their preparedness for participation in the research, electronic questionnaires, which included three sections of demographic characteristics, evaluation of dysfunctional attitudes, and COVID-19 preventive healthy behaviors, were provided to the subjects online. It is notable that the participants were ensured of confidentiality terms regarding their personal information. Overall, 498 individuals filled the questionnaire throughout a month. The questionnaire was designed in a way that access to the next question was subject to answering the previous question. Therefore, there was no incomplete questionnaire. Following data collection and removal of eight outliers, data analysis was performed in SPSS version 21 using Pearson's correlation coefficient and stepwise multiple regression analysis. The inclusion criteria were age over 18 years and elementary school degree.

\subsection{Research Tools}

(1) Demographic characteristics: include five questions about age, marital status, gender, economic status, and level of education of the participants. The questions were of multiple-choice type.

(2) Dysfunctional attitude scale (DAS-26): developed by Weisman and Beck based on Beck's cognitive theory in 1987 , the scale encompasses 40 questions. However, the revised form of the tool includes 26 items scored based on a seven-point Likert scale. In addition, the score range of the scale is 26 - 182. The participants were divided into two high-risk and low-risk groups in terms of dysfunctional attitudes based on the cutoff point of 82. In this regard, those obtaining a score above 82 were recognized as highrisk individuals. The scale comprises four subscales of perfectionism, need for approval, need for satisfying others, and vulnerability-performance evaluation. The tool's Cronbach's alpha was 0.92, correlation with the original form was 0.97 , and validity was confirmed by Ebrahimi et al. (2008) at 0.65 through health prediction with GHQ-28 scores (31). In the present research, Cronbach's alpha was estimated at 0.86 .

(3) COVID-19 Preventive Health Behaviors Questionnaire: this is a researcher-made questionnaire designed in 2020 based on the health protocols announced by the WHO to prevent COVID-19. The tool was formerly assessed and confirmed by several experts in the field in terms of content. In addition, the questionnaire was used in a group of individuals as a test. In total, the tool encompasses eight items, scored based on a five-point Likert scale. In addition, the score range of the tool is $8-40$, where a higher score is indicative of more healthy behaviors. Notably, the Cronbach's alpha of the questionnaire was estimated at 0.70 in the current research.

\section{Results}

Table 1 presents the demographic characteristics of the participants. According to Table 2, there was a reverse relationship between dysfunctional attitude and some of its components (perfectionism and need for satisfying others) with COVID-19 preventive health behaviors $(\mathrm{P}=0.001)$. among the demographic characteristics, there was a reverse significant association between COVID-19 preventive health behaviors and variables of the level of education and economic status $(\mathrm{P}<0.001)$. in addition, a significant relationship was observed between COVID-19 preventive health behaviors and variables of gender and marital status. According to Table 3, the F value of the regression model was equal to 21.357, and 0.109 of the total variances of healthy behaviors were justified and predicted by age, perfectionism, and gender. Even though the value was very low, the regression model was significant. According to t-test results, there was a significant association between COVID-19 preventive health behaviors and the variables of age, perfectionism, and gender $(\mathrm{P}=0.001)$. The correlation between demographic characteristics and dysfunctional attitudes with healthy behaviors was compared between Iran and other countries evaluated in the present research. According to the results, there was a significant reverse correlation between dysfunctional attitudes and healthy behaviors in Iran $(\mathrm{P}<0.001)$. However, this significant relationship was not observed in other countries. According to the results, while a significant relationship was detected between healthy behaviors and the variables of marital status, age, level of education, gender $(\mathrm{P}<0.001)$, and economic status $(\mathrm{P}<0.05)$, no significant association was observed in other studies in this regard.

\section{Discussion}

Performing healthy behaviors and self-care tasks is a valuable step toward increasing awareness and helping people to prevent diseases. Patients can affect their functional abilities and disease course by acquiring self-care skills (9). According to the results of the present study, there was a significant reverse relationship between dysfunctional attitudes and their components (perfectionism and need for satisfying others) and performing healthy behaviors during crises such as the COVID-19 outbreak. In the last step, perfectionism, gender, and age were the factors that remained significant in the equation of predicting healthy behaviors (19, 21, 24-27). 


\begin{tabular}{|c|c|c|}
\hline Variable & Percentage (\%) & Standard Deviation \\
\hline Age (y) & & 1.21 \\
\hline$<20$ & 8.4 & \\
\hline $21-40$ & 56.2 & \\
\hline $41-60$ & 31.4 & \\
\hline$>60$ & 4.0 & \\
\hline \multicolumn{3}{|l|}{ Gender } \\
\hline Female & 80.9 & \\
\hline Male & 19.1 & \\
\hline marital status & & 0.53 \\
\hline Single & 36.3 & \\
\hline Married & 60.6 & \\
\hline Divorced & 3.1 & \\
\hline Level of education & & 0.73 \\
\hline $\begin{array}{l}\text { Elementary/junior high } \\
\text { school }\end{array}$ & 0.4 & \\
\hline High school/diploma & 17.9 & \\
\hline Associate degree/BSc & 43.6 & \\
\hline MSc/higher degrees & 38.1 & \\
\hline Occupational status & & 1.87 \\
\hline Employed & 34.9 & \\
\hline Housewife & 20.1 & \\
\hline Student & 16.3 & \\
\hline Self-employed & 13.5 & \\
\hline Retired & 4.4 & \\
\hline Unemployed & 10.8 & \\
\hline Economic status & & 20.1 \\
\hline Poor & 14.9 & \\
\hline Below moderate & 22.3 & \\
\hline Moderate & 36.1 & \\
\hline Above moderate & 13.3 & \\
\hline High & 13.4 & \\
\hline
\end{tabular}

Increasing evidence from the field of health psychology, which studies the relationship between psychological and health variables, suggests that both health and disease are actually determined by complex interactions between genetic, psychological, and social factors. In addition to the effect of exposure to pathogenic organisms, attitudes, and beliefs, various methods of dealing with mental pressure, individual traits that play a role in our health, and lifestyle of individuals are effective in this regard as well (32). We can explain our findings by referring to the cognitive approach in psychology, according to which irrational

\begin{tabular}{lc}
\hline $\begin{array}{l}\text { Table 2. Matrix of Correlation Between Demographic Characteristics, Dysfunctional } \\
\text { Attitudes, and Related Components and CoviD-19 Preventive Healthy Behaviors }\end{array}$ \\
\hline & Healthy Behaviors \\
\hline Dysfunctional attitudes & $-0.164^{* *}$ \\
\hline Perfectionism & $0.217^{* *}$ \\
\hline Need for approval & -0.029 \\
\hline Need for satisfying others & $-0.124^{* *}$ \\
\hline Vulnerability & 0.040 \\
\hline Level of education & $-0.138^{* *}$ \\
\hline Age & $0.230^{* *}$ \\
\hline Economic status & -0.008 \\
\hline
\end{tabular}

beliefs and how to process information by individuals determine their emotions, attitudes, and behaviors. In a research, five categories of diabetic patients with various attitudes were evaluated, and the results showed that the different attitudes of the participants in each group affected the behaviors related to their disease, resulting in various self-care commitment degrees (33). In another study, researchers assessed the health status of a group of students one year after evaluating their attitudes. According to the results, people with pessimistic attitudes were infected by infectious diseases twice the time that observed in individuals with an optimistic attitude (34).

Attitudes can be dysfunctional and inconsistent and an axis for distorting thinking and behavior. Attitudes are a valid example of traumatic childhood experiences that gradually become established as patterns of distorted thinking and dysfunctional behaviors and become habitual and continuous as they develop into childhood (35). In crises such as the COVID-19 outbreak, dysfunctional attitudes increase anger, stress, anxiety, and feelings of insecurity in interpersonal relationships, resulting in decreased social functioning. Therefore, an individual may pay less attention to healthy behaviors in this respect. When people have dysfunctional attitudes, they may become pessimistic about the impact of their behavior on their destiny and life, and pass this sense of inefficiency on to their other experiences, and neglect many opportunities. This may lead to feelings of helplessness (36), which reduces selfcare behaviors. In another study, individuals with dysfunctional attitudes had lower social functioning and quality of life, compared to healthy people (14). Characteristics of dysfunctional attitudes can be negative and destructive, and an increased dysfunctional attitude towards life events in a person can be accompanied by a feeling of mental pressure. Generally, individuals with positive and hopeful attitudes and away from intellectual errors, consider problems creatively and flexibly and plan to solve them. 


\begin{tabular}{|c|c|c|c|c|c|c|c|c|}
\hline Resources & $\mathbf{R}$ & $\mathbf{R}^{2}$ & Adjusted R & $\mathbf{F}$ & sig & B & $\beta$ & $\mathbf{t}$ \\
\hline Age & 0.339 & 0.115 & 0.109 & 21.357 & 0.001 & 0.705 & 0.216 & 5.050 \\
\hline Perfectionism & & & & & & -0.065 & -0.198 & -4.629 \\
\hline Gender & & & & & & -1.644 & -0.161 & -3.793 \\
\hline
\end{tabular}

In addition, they do not hesitate to ask for help from others when they need it, and they have complete resources to deal with problems, which make them more physically and mentally healthy (19).

In the present study, there was a significant but negative relationship between perfectionism and healthy behaviors. The DAS emphasizes the uncompromising aspect of totalitarianism (self-critical perfectionism), and this type of perfectionism mostly includes extreme selfassessments and critical assessments of individual behavior and difficulty in feeling satisfied with one's behavior. Therefore, this negative relationship can be explained by the fact that the tendency to set extreme and unrealistic standards destroys and weakens the psycho-social activity of individuals. Given that this is a self-assessment tool, perfectionists may have more negative evaluations of their healthy behaviors and have lower scores in performing these behaviors while, in fact, it is not true. Research also shows that extreme self-criticism in the face of adverse life events causes the onset of depressive symptoms as a vulnerability (37). Depression can also be one of the factors that undermine healthy behaviors and the use of non-adaptive coping strategies in the face of negative and stressful events in life. Depression can also be one of the factors that undermine healthy behaviors and the use of non-adaptive coping strategies in the face of negative and stressful events in life.

According to the results of the current research, age was an effective factor regarding the ability to predict healthy behaviors, and those at higher ages had better selfcare performance. In research by Bahrami et al. (2014), there was a negative association between age and self-care level. Regarding our findings, it could be that in the case of COVID-19 disease, a number of underlying factors such as diabetes, cardiovascular disease, and age increase the vulnerability of people to this disease. Therefore, older people need more self-care to survive the disease due to an increase in underlying diseases and a weakened immune system. As such, aging is associated with a higher possibility of self-care in this disease. In the current research, married individuals showed more healthy behaviors, which is consistent with previous studies $(10,29)$. Marriage affects a person's self-care ability with the role that a spouse can play in reducing stress through emotional support and helping to change lifestyles (38). In the present study, there was a significant positive association between the level of education and adopting healthy behaviors, which is in line with the results of previous studies $(28,29)$. A study of the health status of Swedish mothers also showed that a lower level of education was associated with increased mortality, poverty, and poor health behaviors (10).

\subsection{Conclusion}

In the present study, there was a significant, but poor, relationship between dysfunctional attitudes and COVID19. The comparison made between Iran and other countries revealed a significant association between dysfunctional attitudes and healthy behaviors in Iran and no relationship in other countries in this regard. This poor relationship or lack of relationship could be due to the influence of several other factors (e.g., culture, equipment availability, sufficient informing, and social level) on performing self-care behaviors in addition to individuals' attitudes. The difference between Iran and other countries might be due to the difference in the number of participants in Iran and other countries since this number was several times higher in Iran, compared to other countries.

One of the major drawbacks of the present study was the sole participation of those who access the Internet. Another limitation was the relatively low number of subjects in other studies, for which it is recommended that the research be conducted on a higher number of individuals to be able to generalize the results. In addition, since the process of questionnaire completion could not be supervised, it is suggested that future studies be carried out by interviews. This is mainly due to the fact that perfectionists may have a critical and negative view of their healthy behaviors and not evaluate themselves properly. Furthermore, it is recommended that workshops be held for changing dysfunctional attitudes and empowering positive attitudes of community members in-person or via cyberspace before or during crises such as COVID-19. The results of the present study can be used by psychologists and counselors.

\section{Acknowledgments}

Hereby, we extend our gratitude to all the individuals who assisted us in performing the research. 


\section{Footnotes}

Authors' Contribution: Study concept and design: S.E., J.K., S.E, and P. V.; analysis and interpretation of data: S.E., and J.K.; drafting of the manuscript: S. A.; critical revision of the manuscript for important intellectual content: S.E., and J.K.; statistical analysis: S.E., and J.K.: Collecting data: S.E., S.E, and P. V.

\section{Conflict of Interests: There's no conflict of interest.}

Funding/Support: This study was not supported.

\section{References}

1. Tang W, Hu T, Hu B, Jin C, Wang G, Xie C, et al. Prevalence and correlates of PTSD and depressive symptoms one month after the outbreak of the COVID-19 epidemic in a sample of homequarantined Chinese university students. J Affect Disord. 2020;274:1-7. doi: 10.1016/j.jad.2020.05.009. [PubMed: 32405111]. [PubMed Central: PMC7217769].

2. Shi Y, Wang J, Yang Y, Wang Z, Wang G, Hashimoto K, et al. Knowledge and attitudes of medical staff in Chinese psychiatric hospitals regarding COVID-19. Brain Behav Immun Health. 2020;4:100064. doi: 10.1016/j.bbih.2020.100064. [PubMed: 32289123]. [PubMed Central: PMC7138160].

3. Shigemura J, Ursano RJ, Morganstein JC, Kurosawa M, Benedek DM. Public responses to the novel 2019 coronavirus (2019-nCoV) in Japan: Mental health consequences and target populations. Psychiatry Clin Neurosci.2020;74(4):281-2. doi:10.1111/pcn.12988. [PubMed:32034840]. [PubMed Central: PMC7168047].

4. Varalakshmi R, Swetha R. Covid-19 lock down: People psychology due to law enforcement. Asian J Psychiatr. 2020;51:102102. doi: 10.1016/j.ajp.2020.102102. [PubMed: 32344332]. [PubMed Central: PMC7162767].

5. Farnoosh G, Alishiri G, Hosseini Zijoud SR, Dorostkar R, Jalali Farahani A. [Understanding the severe acute respiratory syndrome coronavirus 2 (SARS-CoV-2) and coronavirus disease (COVID-19) based on available evidence - a narrative review]. J Military Med. 2020;22(1):1-11. Persian. doi: 10.30491/jmm.22.1.1.

6. Guan Y, Deng H, Zhou X. Understanding the impact of the COVID19 pandemic on career development: Insights from cultural psychology. J Vocat Behav. 2020;119:103438. doi: 10.1016/j.jvb.2020.103438. [PubMed: 32382162]. [PubMed Central: PMC7204647].

7. Keshtkaran Z, Ghodsbin F, Solouki S, Razeghi M,Zare N. The impact of self care education on quality of life of those clients suffering from osteoarthritis in rehabilitation centers of Shiraz university of medical science (Iran).JBUMS. 2010;12(1(54)). Persian.

8. WHO. The role of the pharmacist in self-care and self-medication, report of the 4th WHO consultative group on the role of the pharmacist. 2008.

9. Shojaei F, Asemi S, Najaf Yarandi A, Hosseini F. [Self- care behaviors in patients with heart failure]. Payesh. 2009;8(4):361-9. Persian.

10. Bahrami N, Pajouhideh Z, Mohammadi SKS, Maraghi E. [Attitude and practice towards self-care in women referred to health centers in Dezful]. Community Health. 2015;2(1):50-6. Persian.

11. Hamedanizadeh F, Mahmoudzadeh Zarandi F, Ebadi A, Asad Zandi M, Kachouei H. [Effectiveness of implementation of orem selfcare program on headache indices in migraineur]. Kowsar Med J. 2010;15(3):155-61. Persian.

12. Baghaei P,Zandi M, Vares Z, Masoudi Alavi N, Adib-Hajbaghery M. [Self care situation in diabetic patients referring to Kashan Diabetes Center, in 2005]. Feyz J Kashan Univ Med Sci. 2008;12(1):88-93. Persian.

13. Mionk EM, Mahmood Z. Student mental health: A pilot study. Couns Psychol Q. 2007;12(2):199-210. doi:10.1080/09515079908254090.
14. Kërqeli A, Kelpi M, Tsigilis N. Dysfunctional attitudes and their effect on depression. Procedia Soc Behav Sci. 2013;84:196-204. doi: 10.1016/j.sbspro.2013.06.534.

15. Ebrahimi A, Neshatdoost H, Kalantari M, Molavi H, Asadollahi G. [Contributions of dysfunctional attitude scale and general health subscales to prediction and odds ratio of depression]. J Shahrekord Univ Med Sci. 2008;9(4):52-8. Persian.

16. Rabiei M, Molavi H, Kalantari M, Azimi H. [The relationship between dysfunctional attitudes and coping strategies with mental health].J New Educ Approaches. 2009;4(2):21-30. Persian.

17. Davison G, Kering A, Neil J. [Psychopathology. Translated by Mehdi Dehestani (1389)]. Tehran; 1939. Persian.

18. Kasiske BL, Snyder JJ, Gilbertson DT, Simon T, Maclean JR. Risk factors for post-kidney transplant depression identify which patients need closer mental health assessment. American Society of Nephrology 37th Annual Meeting \& Scientific Exposition. St Louis. 2004.154 p.

19. Hajiriloo S, Khoshnevis E, Ghodrati S. [Effect of self-care training on dysfunctional attitudes in volunteer women of instructing children's sexual education]. Fam Pathol, Couns Enrich J. 2019;5(1):77-90. Persian.

20. Samsam Shariat SMR, Taher Neshatdoost H, Kalantari M, Oreyzi Samani SHR. [Comparing the effectiveness of cognitive behavior therapy and psychosocial therapy on rumination and dysfunctional at titude in patients with chronic depression]. Res Clin Psychol Couns. 2019;9(1 g00963). Persian.

21. Stadick JL. The relationship between interprofessional education and health care professional's attitudes towards teamwork and interprofessional collaborative competencies. J Interprof Educ Pract. 2020;19:100320. doi:10.1016/j.xjep.2020.100320.

22. Mogre V, Johnson NA, Tzelepis F, Hall A, Paul C. Barriers to self-care and their association with poor adherence to self-care behaviours in people with type 2 diabetes in Ghana: A cross sectional study. Obes Med.2020;18:100222. doi:10.1016/j.obmed.2020.100222.

23. Shibayama T, Tanha S, Abe Y, Haginoya H, Rajab A, Hidaka K. The role of illness schemata in self-care behaviors and glycemic control among patients with type 2 diabetes in Iran. Prim Care Diabetes. 2019;13(5):474-80. doi: 10.1016/j.pcd.2019.03.002. [PubMed: 30926384].

24. Mirkarimi SK, Aryaie M, Kamran A, Farid H. [Knowledge, attitude and practice of women referred to health centers of Gorgan on the determining factors of self-care].Jorjani Biomed J. 2014;2(2):58-0. Persian.

25. Hagemeister MH, Stock NK, Ludwig T, Heuschmann P, Vogel U. Self-reported influenza vaccination rates and attitudes towards vaccination among health care workers: results of a survey in a German university hospital. Public Health. 2018;154:102-9. doi: 10.1016/j.puhe.2017.10.027. [PubMed: 29220709].

26. Ellis A. The revised ABC's of rational-emotive therapy (RET). J Ration Emot Cogn Behav Ther. 1991;9(3):139-72. doi:10.1007/bf01061227.

27. Crano WD, Prislin R. Attitude and attitude change. London: Taylor \& Fravcis Group; 2008. p. 74-305.

28. Didarloo A, Shojaeizadeh D, Ardebili HE, Niknami S, Hajizadeh E, Alizadeh M. Factors influencing physical activity behavior among Iranian women with type 2 diabetes using the extended theory of reasoned action. Diabetes Metab J. 2011;35(5):513-22. doi 10.4093/dmj.2011.35.5.513. [PubMed: 22111043]. [PubMed Central: PMC3221027]

29. Zajacova A. Education, gender, and mortality: does schooling have the same effect on mortality for men and women in the US? Soc Sci Med. 2006;63(8):2176-90. doi: 10.1016/j.socscimed.2006.04.031. [PubMed: 16781036].

30. Abootalebi Daryasari G, Vosoghi Karkezloo N, Mohammad Nejad E, Namadi Vosooghi M, Akbari Kagi M. [Study of the self-care agency in patients with heart failure]. Iran J Crit Care Nurs. 2012;4(4). Persian.

31. Karimi S, Javadi M, Jafarzadeh F. [Economic burden and costs of chronic diseases in Iran and the world]. Health Inf Manag J. 2012;8(7):984-96. Persian. 
32. Bashiri H, Dehghan F, Saeedi S, MehrabiPari S, ShafieiKohnehshahri S, Abaszadeh M. [Relationship between Looming Cognitive Style with Dysfunctional Attitudes, Anxiety, and Depression among Cancer Patients]. J Health Care. 2018;19(4):242-50. Persian.

33. Barn R, Byrne D, Burnscomb N. [Social psychology. Translated by Yousef Karimi (1392)]. Tehran: Ravan Publishing; 2006. Persian.

34. Mosnier-Pudar H, Hochberg G, Eschwege E, Halimi S, Virally ML, Guillausseau PJ, et al. How patients' attitudes and opinions influence self-care behaviours in type 2 diabetes. Insights from the French DIABASIS Survey. Diabetes Metab. 2010;36(6 Pt 1):476-83. doi: 10.1016/j.diabet.2010.08.004. [PubMed: 20947405].

35. Seligman ME, Csikszentmihalyi M. Positive psychology: An introduction. American Psychologist. 2000;55(1):5-14. doi: 10.1037/0003- 066x.55.1.5.

36. Zorrahim R, Beyrami M. [Relationship between dysfunctional attitudes with the components of psychological well-being in students of Islamic Azad University of Tabriz]. Community Health J. 2015;9(3):917. Persian.

37. Rakrava M, Omranifard V, Ebrahimi A, Atapour A, Mortazavi M. [Relationship between quality of life, general health and dysfunctional attitudes in kidney transplant patients].J Res Behave Sci. 2015;12(4). Persian.

38. Shokri O, Pour Shahriar H, Aghayi M, Sanayi pour MH. [Psychometric analysis scale of dysfunctional attitude towards children and adolescents]. J Thought Behav Clin Psychol. 2015;9(36):47-57. Persian. 